\title{
Sorption of rare earth elements on schwertmannite and their mobility in acid mine drainage treatments
}

\author{
Alba Lozano ${ }^{a, b^{*}}$, Carlos Ayora ${ }^{a, b}$, Alejandro Fernández-Martínez ${ }^{c}$ \\ ${ }^{a}$ Institute of Environmental Assessment and Water Research, (IDAEA-CSIC), Jordi Girona 18-26, 08034 \\ Barcelona, Spain \\ ${ }^{b}$ Grup de Mineralogia Aplicada i Geoquímica de Fluids, Departament de Cristal-lografia, Mineralogia i \\ Dipòsits Minerals, Facultat de Geologia, Universitat de Barcelona (UB), C/Martí Franquès, S/N, \\ Barcelona, Spain \\ ' Univ. Grenoble Alpes, Univ. Savoie Mont Blanc, CNRS, IRD, IFSTTAR, ISTerre, 38000 Grenoble, France
}

Corresponding author:

Alba Lozano (alba.lozano@idaea.csic.es) 


\begin{abstract}
Rare earth elements (REE) are currently considered critical raw materials due to their increasing use in modern technologies and their shortage of supply. Acid mine drainage (AMD) contains REE concentrations that are several orders of magnitude higher than those in continental and marine waters, and the sludge resulting from AMD treatment can become a supplementary source of REE. Schwertmannite, an Fe(III)-sulfate-hydroxide, is the most common mineral precipitated from $A M D$ and is a main constituent of treatment sludge. The objective of this work was to study the mechanisms of REE retention in schwertmannite.

Suspensions of synthetic schwertmannite in sulfate solutions showed that $\mathrm{Y}$ and the lanthanides are effectively sorbed at $\mathrm{pH}$ values higher than 4.5 , and sorption is complete at $\mathrm{pH}$ values higher than 6.5. The experimental partition coefficients clearly show a preferential enrichment of heavy REE (HREE) in the solid phase. Unlike the rest of the REE, Sc sorption occurred at a lower $\mathrm{pH}$, from 3 to 5 . The experimental results have been described with a nonelectrostatic surface complexation model in which the aqueous complex $\mathrm{MSO}_{4}{ }^{+}$exchanges with two $\mathrm{H}^{+}$from the surface of schwertmannite, forming bidentate surface complexes, $(\mathrm{XO})_{2} \mathrm{MSO}_{4}^{-}$. Sc sorption was also accurately predicted with the addition of two bidentate surface complexes, $(\mathrm{XO})_{2} \mathrm{MSO}_{4}^{-}$and $(\mathrm{XO})_{2} \mathrm{MOH}$.

The model was successfully applied to describe the behavior of different REE observed in a column experiment imitating an AMD passive remediation system. Both basaluminite and schwertmannite were the main solid phases formed in the treatment. Although both minerals have similar sorption edges, $\mathrm{Y}$ and the lanthanides sorbed at $\mathrm{pH}$ values higher than 4.5 , and sorption only occurred on basaluminite because schwertmannite forms at a $\mathrm{pH}$ below 4 . In contrast, the Sc sorption edge extends from pH 3 to 5 and therefore can partially sorb on schwertmannite. As a practical consequence, REE preferentially accumulated in basaluminite residue of AMD neutralization systems, with only a minor but a significant fraction of Sc found in schwertmannite sludge.
\end{abstract}

\title{
Keywords
}

Scandium, yttrium, lanthanides, non-electrostatic model, bidentate surface complex, acid mine drainage, passive remediation, neutralization sludge 


\section{Introduction}

The rare earth elements (REE) form the largest chemically coherent group in the periodic table. According to the International Union of Pure and Applied Chemistry, REE are formed by the lanthanide series elements yttrium and scandium. Their similar atomic structure and chemical properties, as well as the small differences among the elements in the group, convert their partition between water and minerals as tracers of geochemical processes (Henderson, 1984; Elderfield et al., 1990; Johanesson et al., 1999, among many others). Beyond their importance as geochemical tracers, in the last two decades, there has been an increasing interest in REE due to their high demand by modern industry. This demand, together with a relative shortage of supply, has motivated the search for alternative sources of REE raw materials worldwide (Hatch, 2012; Massari and Ruberti, 2013).

On the other hand, acid mine drainage (AMD) is one of the most important and widespread pollutants affecting watersheds and ecosystems (Nordstrom et al., 2015). However, AMD could also become a new and supplementary source for REE, including scandium, because the concentration of REE in AMD is two to three orders of magnitude higher than that in natural waters (Noack et al., 2014). In AMD, not only pH but also aqueous speciation are key factors for REE mobility. Thus, the $\mathrm{pH}$ increases to circumneutral values when AMD mixes with alkaline waters, leading to the precipitation of hydrous ferric/aluminum oxides and sulfate-hydroxides, which is accompanied by REE scavenging (Verplanck et al. 2004; Gammons et al., 2005 a, b; Ferreira da Silva et al., 2009). However, despite the overwhelming presence of REE as precipitates in AMD streams (Nordstrom, 2011), there is a lack of knowledge on the interaction mechanisms between schwertmannite and REE and their dependence on $\mathrm{pH}$ and sulfate concentration.

In addition to REE, AMD also contains high concentrations of toxic elements and represents a very important environmental threat that requires remediation. In mine operations, active AMD treatment is mainly based on its neutralization with alkaline reagents, usually lime, limestone, sodium carbonate or ammonia (Evangelou and Zhang, 1995; Coulton et al., 2003). This treatment produces high amounts of sludge formed by a mixture of Fe(III) and Al-sulfatehydroxides, disposal of which represents a major operating cost for companies and an important environmental concern (Ackman, 1982; Viadero et al., 2006). In contrast, passive remediation systems neutralize AMD by driving it through a permeable system filled with grained limestone (Heding et al., 1994; Ayora et al., 2013). Along the process, the created waste is represented by a sequential precipitation of mainly schwertmannite $\left[\mathrm{Fe}_{8} \mathrm{O}_{8}(\mathrm{OH})_{6} \mathrm{SO}_{4}\right]$ and basaluminite $\left[\mathrm{Al}_{4} \mathrm{SO}_{4}(\mathrm{OH})_{10} \cdot 5 \mathrm{H}_{2} \mathrm{O}\right]$, clearly identified in two separated layers. Although scandium was not included, essentially all the lanthanide and yttrium content in the inflowing AMD were retained in the treatment, particularly in the basaluminite layer (Ayora et al., 2016). Consequently, the sorption of REEs on basaluminite and the dependence of this process on $\mathrm{pH}$ and sulfate availability has been recently studied (Lozano et al., 2019). However, despite being a major constituent of AMD treatment sludge, the interaction between schwertmannite and REEs remains unknown.

Previous laboratory experiments of sorption and coprecipitation of REE onto ferric and manganese oxides/hydroxides have previously demonstrated the key role of $\mathrm{pH}$ in the geochemical mobility of REE (De Carlo et al., 1998; Bau 1999; Ohta and Kawabe 2000a; Ohta 
and Kawabe 2001; Quinn et al., 2004, 2006a). REE are removed from solution as the pH increases from 4 to 9 . In addition to $\mathrm{pH}$, aqueous speciation is also an important factor that has been widely studied in REE fractionation in marine environments. Thus, the formation of strong carbonate complexes with heavy REE (HREE) at neutral pH values prevents their sorption by ferric and manganese oxides. As a result, these solids show patterns with light REE (LREE) enrichment (Byrne and Kim, 1990; Koeppenkastrop and De Carlo, 1992; Sholkovitz, 1995; Byrne and Sholkovitz, 1996; Kawabe et al., 1999). More recently, some works have performed detailed sorption experiments and developed surface complexation models to describe the sorption of some lanthanides ( $\mathrm{Yb}, \mathrm{La}, \mathrm{Eu}$ ) onto hematite and amorphous ferric oxides/hydroxides (Marmier et al., 1997; Rabung et al., 1998; Marmier and Fromage, 1999; Quinn et al., 2006; Estes et al., 2013; Liu, 2017). REE scavenging is mainly explained by the sorption of free REE ions or their hydrolyzed species onto a solid surface.

The presence of sulfate is ubiquitous in AMD systems, usually with concentrations reaching up to several grams per liter. Rather than free ions or hydrolysis products, previous studies have highlighted the importance of aqueous sulfate complexed with REEs (Johanneson and Lyons, 1995; Gimeno et al., 2000; Verplanck et al., 2004). Similar to REE-carbonate speciation in seawater, sulfate complexes may explain REE fractionation in the solids precipitated from AMD environments. Therefore, due to its importance in AMD chemistry, the role of sulfate in REE sorption on schwertmannite should be quantitatively assessed.

Here, we present the results from REE sorption experiments on synthetic schwertmannite in a sulfate-rich AMD setting. A non-electrostatic surface complexation model was developed to describe the experimental data for the sorption of a complete data set of REE (the lanthanides, $\mathrm{Y}$ and $\mathrm{Sc}$ ) at different $\mathrm{pH}$ values, sulfate concentrations and solid:liquid ratios. The model was then applied to predict the mobility of different REE during a passive AMD neutralization system, and the results are compared with those obtained from a column experiment.

\section{Materials and methods}

\subsection{Experimental techniques}

\subsubsection{Structural characterization of synthetic schwertmannite}

Synthetic schwertmannite was prepared following the procedure described by Cornell and Schwertmann (1996), where $10.8 \mathrm{~g}$ of $\mathrm{FeCl}_{3} \cdot 6 \mathrm{H}_{2} \mathrm{O}$ and $3 \mathrm{~g}$ of $\mathrm{Na}_{2} \mathrm{SO}_{4}$ were mixed with $2 \mathrm{~L}$ of distilled water at $60^{\circ} \mathrm{C}$. The suspension was stirred for 12 minutes at $60^{\circ} \mathrm{C}$ and then cooled to room temperature. The solid was dialyzed in a cellulose membrane against double-distilled water for 33 days. Once the water had conductivity less than $0.5 \mathrm{~ms} / \mathrm{cm}$, the precipitate was freeze-dried. Mineral purity was assessed by X-ray diffraction (XRD). The specific surface area was measured by the BET- $\mathrm{N}_{2}$ sorption method (Micromeritics Gemini $V$ analyzer; Micromeritics, IDAEA-CSIC).

\subsubsection{REE sorption as a function of $\mathrm{pH}$ and sulfate concentration}

The REE sorption on synthetic schwertmannite was measured as a function of $\mathrm{pH}$ at two different sulfate concentrations in two separate sets of batch experiments using suspensions of $1 \mathrm{~g} / \mathrm{L}$. Two stock solutions with a $\mathrm{pH}$ of 2.5 were prepared for each set. The first stock 
solution consisted of REEs at a concentration of $1 \mathrm{mg} / \mathrm{L}$ each and $20 \mathrm{mM} \mathrm{SO}_{4}$, whereas the second stock solution consisted of REEs at a concentration of $1 \mathrm{mg} / \mathrm{L}$ each and $2 \mathrm{mM} \mathrm{SO}_{4}$. The solutions were prepared with an ICP standard mix of 16 elements, excluding $\mathrm{Pm}$, and $\mathrm{Na}_{2} \mathrm{SO}_{4}$ (ACS reagent $>99.9 \%$, Merck). The stock solutions were intended to simulate acid mine waters with different sulfate concentrations. First, $10-\mathrm{mL}$ aliquots of each stock solution were transferred to $50-\mathrm{mL}$ centrifuge tubes, and the $\mathrm{pH}$ of each aliquot was adjusted to cover a $\mathrm{pH}$ range of 3-7 by adding small amounts of a $0.05 \mathrm{M} \mathrm{NH}_{4} \mathrm{OH}$ solution. After adding $10 \mathrm{mg}$ of schwertmannite to each aliquot, the suspensions were shaken for 6 hours at room temperature. Then, the suspensions were centrifuged for 15 minutes at $4500 \mathrm{rpm}$ (4150 RCF), and the supernatant was filtered through $0.22-\mu \mathrm{m}$ nylon membranes and transferred to test tubes diluted fivefold with $1 \% \mathrm{HNO}_{3}$. The solids were dried at $40^{\circ} \mathrm{C}$ for 48 hours. The sorbed fractions were calculated as follows:

Sorbed fraction $=\frac{[\mathrm{REE}]_{\text {initial }}-[\mathrm{REE}]_{\text {final }}}{[\mathrm{REE}]_{\text {initial }}}$

where [REE] is the concentration of each REE. The initial concentration was measured in the stock solution and the final concentration after the experiment. The distribution coefficient, $K_{D}$ $(\mathrm{L} / \mathrm{kg})$, for each REE was calculated from the [REE] sorbed onto the solid per the final [REE] remaining in solution and normalized per the solid:liquid ratio:

$\mathrm{K}_{\mathrm{D}}=\frac{[\mathrm{REE}]_{\text {initial }}-[\mathrm{REE}]_{\text {final }}}{[\mathrm{REE}]_{\text {final }}} \cdot \frac{\mathrm{V}_{\text {solution }}}{\mathrm{M}_{\text {solid }}}$

\subsubsection{Description of the column experiment and waste characterization}

To obtain a complete vertical profile of REE distribution in the pore water and of the minerals precipitated along a passive AMD remediation system, a scaled column experiment was carried out. The column was built with transparent polymethyl methacrylate $(9.6-\mathrm{cm}$ inner diameter and $35 \mathrm{~cm}$ in height). A $3-\mathrm{cm}$ layer of glass beads ( $3 \mathrm{~mm}$ in diameter) and a perforated drainpipe were installed at the bottom of the column. Lateral ports located at $3-\mathrm{cm}$ intervals in the upper part of the column allowed pore water sampling. The column was filled with $20 \mathrm{~cm}$ of dispersed alkaline substrate consisting of $30 \mathrm{~g}$ of limestone sand $(0.5-1 \mathrm{~mm})$ and $300 \mathrm{~g}$ of pine-wood shavings $(5-10 \mathrm{~mm}$ ) (Rötting et al., 2008a). The role of the pine-wood shavings was to provide a porous matrix to allocate the minerals that precipitated inside the column and prevent clogging. The proportion of limestone was predesigned to be small in order to exhaust the reagent within a few weeks. The initial total porosity of the filling was determined to be 0.46 , first by weighing the column filled with only the solid phase and then again with the column pores saturated with water.

A sample of AMD from the Poderosa mine in the Iberian Pyrite Belt (SW Spain) was used as the REE-containing inflow to the column. The column was open to the atmosphere, and the input AMD was pumped into the top of the column with a peristaltic pump. The water flowed downward by gravity through the limestone substrate at a constant flow rate of $3.5 \mathrm{~mL} / \mathrm{min}$. This flow was similar to that of $2 \mathrm{~L} / \mathrm{s}$, which is the flow rate expected for a field-scale treatment of $200 \mathrm{~m}^{2}$ of surface area to treat the discharge of the Poderosa mine. Water samples were collected every other week from the supernatant, and sampling points and their $\mathrm{pH}$, redox potential, electrical conductivity, oxygen concentration and total alkalinity were measured in situ. The water was filtered through $0.22-\mu \mathrm{m}$ nylon filters and stored at $4^{\circ} \mathrm{C}$ until analysis. The 
experiment lasted for 58 days and was stopped when the outflow showed a $\mathrm{pH}$ lower than 5 , as an indication of reagent efficiency exhaustion.

Postmortem, the columns were drained, and the residue was divided into $2-\mathrm{cm}$ slices and dried at room temperature. The major mineral phases present in the solid residue were identified by XRD. To investigate the partitioning of $\mathrm{Al}, \mathrm{Fe}$, and trace elements into the solid phases, a sequential extraction procedure adapted from Torres and Auleda (2013) was applied to the residue samples to obtain the following fractions: 1 ) the water-soluble fraction, extracted with deionized water; 2 ) calcite and basaluminite, extracted with $1 \mathrm{M}$ ammonium acetate at $\mathrm{pH}$ 4; 3) low crystalline Fe(III)-oxyhydroxides and remaining basaluminite, extracted with $0.2 \mathrm{M}$ ammonium oxalate at $\mathrm{pH} 3$; 4) crystalline Fe(III)-oxides, extracted with $0.2 \mathrm{M}$ ammonium oxalate at $\mathrm{pH} 3$ in a water bath at $80^{\circ} \mathrm{C}$ for 2 hours; and 5) the residual fraction, extracted with concentrated $\mathrm{HClO}_{4}$ and $\mathrm{HNO}_{3}$ at $135^{\circ} \mathrm{C}$. All the leachates resulting from the different extraction steps were filtered through $0.22-\mu \mathrm{m}$ nylon syringe filters and stored at $4^{\circ} \mathrm{C}$ until analysis. Duplicates for $10 \%$ of the total samples were analyzed, showing a reproducibility of $90 \%$. To validate the addition of masses obtained from all the extraction steps, a total digestion (performed according to step 5 of the protocol) of all the samples was conducted. The addition of sequential extractions was compared with the total extraction from the digestion, and only element recovery rates between $80 \%$ and $120 \%$ were considered suitable for discussion.

\subsection{Analytical techniques}

Measurements of $\mathrm{pH}$ from filtered aliquots were made with a Crison ${ }^{\circledR}$ glass electrode calibrated with buffer solutions of $\mathrm{pH} \mathrm{2,} \mathrm{4,7} \mathrm{and} \mathrm{9.} \mathrm{Major} \mathrm{cations} \mathrm{were} \mathrm{measured} \mathrm{by} \mathrm{ICP-AES}$ (Thermo Scientific - iCAP 6500, radial acquisition), and REEs (La, Ce, Pr, Nd, Sm, Eu, Gd, Tb, Dy, $\mathrm{Ho}, \mathrm{Er}, \mathrm{Tm}, \mathrm{Yb}, \mathrm{Lu}, \mathrm{Y}$ and Sc) were measured with ICP-MS (Perkin-Elmer ${ }^{\circledR}$ SciexElan 6000). The detection limits were $0.2 \mu \mathrm{g} / \mathrm{L}$ for REEs and $0.1,0.05,0.1$ and $0.1 \mathrm{mg} / \mathrm{L}$ for $\mathrm{S}, \mathrm{Fe}, \mathrm{Al}$ and $\mathrm{Na}$, respectively. The analytical precision error was estimated to be approximately $2 \%$ for ICP-MS and ICP-AES measurements. Certified solutions (CPI International-CCV standard 1-solution A) were intercalated within the samples to check the analytical accuracy. Two AMD laboratory standards supplied by P. Verplank (USGS) were also analyzed for REE accuracy, yielding deviations lower than $4 \%$ of the recommended values, with the exception of Eu, which showed values $19 \%$ below the recommended value (Verplanck et al., 2001).

The XRD patterns of the solid phases after the experiments were obtained using a Bruker D8 A25 Advance Diffractometer $\theta-\theta$ with CuKa1 radiation. The diffractometer operated at $40 \mathrm{kV}$ and $40 \mathrm{~mA}$ in a Bragg-Brentano geometry and was equipped with a linear LynxEye XE detector. The diffractograms were obtained from $4^{\circ}$ to $60^{\circ}$ in $2 \theta$ with a step size of $0.015^{\circ}$ and a counting time of $0.1 \mathrm{~s}$.

\subsection{Geochemical modeling}

Chemical speciation of dissolved REE, saturation indexes of solid phases, surface complexation and $1 \mathrm{D}$ reactive transport modeling were calculated with the PHREEQC code (Parkhurst and Appelo, 1999) using the database Donnee Thermoddem_V1.10.dat (Blanc et al., 2012). The database has been updated with the stability constants at zero ionic strength and $25^{\circ} \mathrm{C}$ for the following inorganic complexes for the lanthanides and yttrium (M): $\mathrm{MCO}_{3}{ }^{+}, \mathrm{MCO}_{3}{ }^{-2}, \mathrm{MHCO}_{3}{ }^{+2}$ 
(Luo and Byrne, 2004); $\mathrm{MSO}_{4}{ }^{+}$(Schijf and Byrne, 2004); $\mathrm{MOH}^{+2}$ (Klungness and Byrne, 2000); $\mathrm{MOH}_{2}{ }^{+}, \mathrm{MOH}_{3}$ (Lee and Byrne, 1992); $\mathrm{MCl}^{+2}$ (Luo and Byrne, 2001); $\mathrm{MF}^{+2}, \mathrm{MF}_{2}^{+}$(Luo and Millero, 2004); and $\mathrm{MNO}_{3}{ }^{+2}$ (Millero, 1992). Solubility products for REE $\mathrm{M}(\mathrm{OH})_{3}$ and $\mathrm{M}(\mathrm{OH})_{3(\mathrm{am})}$ solids have been complementarily loaded from the LLNL database (Johnson et al., 1992) and Spahiu and Bruno (1995). Scandium aqueous complexes, $\mathrm{Sc}(\mathrm{OH})^{+2}, \mathrm{Sc}(\mathrm{OH})_{2}{ }^{+}, \mathrm{Sc}(\mathrm{OH})_{3}$, and $\mathrm{ScSO}_{4}{ }^{+}$, and the solubility product for $\mathrm{Sc}(\mathrm{OH})_{3}$ by Wood and Samson (2006) were incorporated. The reactions and their equilibrium constants are compiled in Table S1 of the Supplementary Information.

\section{Results}

\subsection{Characterization of synthetic schwertmannite}

The XRD patterns of the solid phase prior to and after the sorption experiments confirmed that the mineral was pure schwertmannite (Fig. S1, S2). The measured specific surface area of pure schwertmannite was $173 \mathrm{~m}^{2} / \mathrm{g}$, close to the values reported by Antelo et al. (2012) and Regenspurg et al. (2004) $\left(171 \mathrm{~m}^{2} / \mathrm{g}\right.$ and $175-200 \mathrm{~m}^{2} / \mathrm{g}$, respectively). The site density was calculated from the crystal structure proposed by Fernández-Martínez et al. (2010), accounting for the single coordinated sites per face area, yielding values of 2 sites/63.22 $\AA^{2}$ for $\left(\begin{array}{lll}1 & 0 & 0\end{array}\right), 7.5$ sites $/ 113.77 \AA^{2}$ for $\left(\begin{array}{lll}0 & 1 & 0\end{array}\right)$ and 2 sites $/ 64.95 \AA^{2}$ for $\left(\begin{array}{llll}0 & 0 & 1\end{array}\right)$ (Fig. S3). These calculations resulted in a total site density of 4.75 sites $/ \mathrm{nm}^{2}$, a value similar to $4.7 \mathrm{sites} / \mathrm{nm}^{2}$ reported by Fukushi et al. (2004). The resulting total concentration of surface sites was therefore $1367 \mu \mathrm{mol} / \mathrm{g}$.

\subsection{REE sorption as a function of $\mathrm{pH}$ and sulfate concentration}

Prior to sorption experiments, the kinetics of the sorption reactions were determined using 10 suspensions of $1 \mathrm{~g} / \mathrm{L}$ schwertmannite and a solution of REE at a concentration of $1 \mathrm{mg} / \mathrm{L}$ each and $20 \mathrm{mM} \mathrm{SO}_{4}$ at $\mathrm{pH}$ 5.5. The kinetics experiments showed a very fast initial sorption, which increased until a steady state was reached at 5 hours (Fig. S4). Similar equilibrium times were observed for ferric oxyhydroxide by Ohta and Kawabe (2001) and Koeppenksastrop and De Carlo (1992), with fast REE adsorption at approximately 4-6 hours. Therefore, sorption was considered almost complete after 6 hours of contact during the sorption experiments.

The chemical composition data of the initial and final solutions for the two sets of sorption experiments with 20 and $2 \mathrm{mM} \mathrm{SO}_{4}$ are compiled in Tables S2 and S3, respectively. All solutions at the end of the sorption experiments were subsaturated with respect to the REE hydroxides (Tables S4, S5), and thus the hydroxide precipitation was discarded. The solutions were also subsaturated with respect to schwertmannite and were almost in equilibrium with respect to goethite. Schwertmannite exists in a metastable phase that transforms to goethite over weeks at different pH values (Schwertmann and Carlson, 2005; Acero et al., 2006; Burton et al., 2009). However, the presence of sulfate in solution delays this transformation (Regenspurg and Peiffer, 2005), and goethite was not detected by XRD in schwertmannite solids after the sorption experiments (Fig. S1, S2).

Sorption showed a high dependence on $\mathrm{pH}$ in the two sets of experiments, as the REE sorption increased with pH (Fig. 1). The sorption edges occurred within a range of 2.0 to $2.5 \mathrm{pH}$ units and shifted to lower $\mathrm{pH}$ values for HREE than for LREE, showing that HREE sorption was 
favored over LREE sorption at the same $\mathrm{pH}$ value. Similar $\mathrm{pH}$ dependence was observed by Bau (1999) and Quinn et al. (2006) in REE coprecipitation with amorphous ferric hydroxide and by Lozano et al. (2019) in REE sorption on basaluminite.

The $\mathrm{pH}$ at which sorption becomes significant depends on the element. The lanthanides and $\mathrm{Y}$ started to sorb at $\mathrm{pH} 5$, whereas Sc started at pH 3.5, a value considerably lower than the rest of the REE. In the experiment with $20 \mathrm{mM} \mathrm{SO}_{4}$ at pH 4.9, more than $95 \%$ of Sc was adsorbed on schwertmannite, whereas less than $20 \%$ of the remaining REE were adsorbed. Similar behavior was also observed for basaluminite (Lozano et al., 2019), although here Sc sorption occurred at a $\mathrm{pH}$ lower than 4 , at which basaluminite is not stable. The preferential Sc sorption onto schwertmannite boosts the interest of Sc recovery from passive remediation waste, during which the schwertmannite layer precipitates are separated from the basaluminite layer. Based on this selective sorption, studies have focused on Sc separation and REE recovery during a two-step adsorption process with synthetic sorbents at $\mathrm{pH} 4$ and 5 , as recently proposed by Ramasamy et al. (2018).
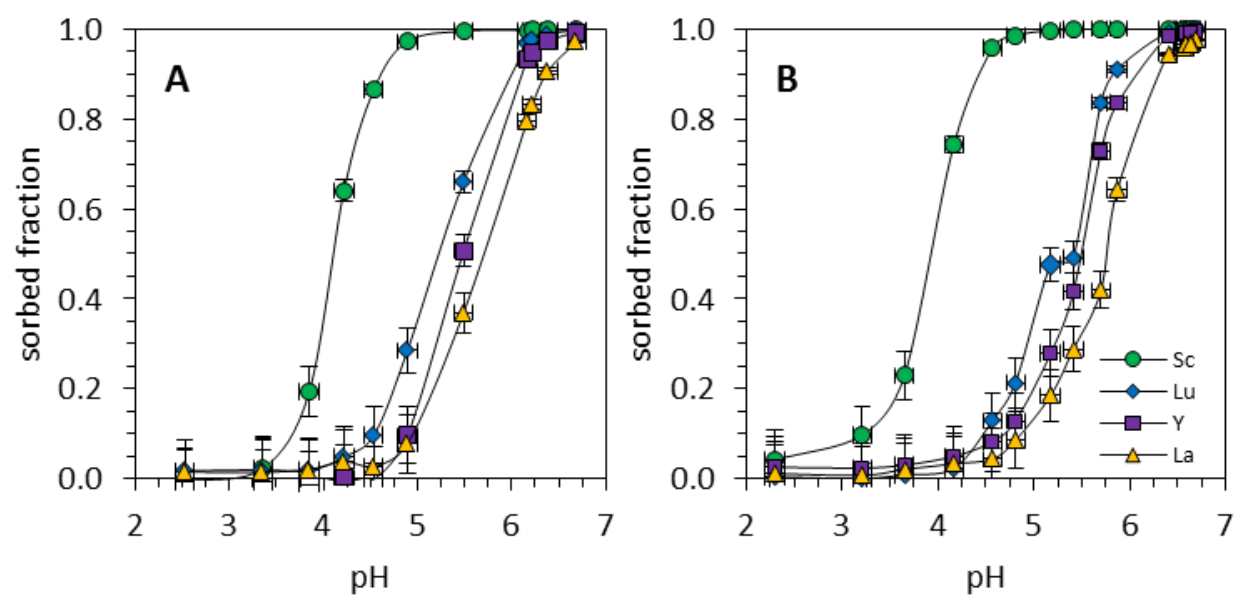

Fig. 1. Sorption edges of selected REE on schwertmannite in solutions with $20 \mathrm{mM}(\mathrm{A})$ and 2 $\mathrm{mM}(\mathrm{B})$ sulfate. Legend: Sc: circles, Y: squares, Lu: squares and La: diamonds. The error bars indicate the uncertainties in $\mathrm{pH}$ measurements $( \pm 0.02)$ and in the sorbed fraction (from \pm 0.01 to \pm 0.07$)$.

The distribution coefficients $\left(K_{D}\right)$ for both sets of experiments were calculated as described in Eq. (2) and are shown in Fig. 2. The REE fractionation patterns showed four convex segments from La to $\mathrm{Nd}$, from $\mathrm{Nd}$ to $\mathrm{Gd}$, from $\mathrm{Gd}$ to $\mathrm{Ho}$ and from Ho to Lu, corresponding to the M-type tetrad effect (Masuda et al., 1987; Bau 1996). The $K_{D}$ values increased by 3 orders of magnitude with $\mathrm{pH}$ increasing from 4.5 to 6.5 , highlighting the dependence of REE sorption on $\mathrm{pH}$. At $\mathrm{pH}$ values higher than 5 , when sorption becomes effective, the $\mathrm{K}_{\mathrm{D}}$ values clearly showed an enrichment of HREEs in the solid phase, which increased by 1 order of magnitude along the lanthanide series. Similar REE patterns with HREE enrichments appeared in free REEs that were coprecipitated with synthetic Fe(III)-hydroxides (De Carlo et al., 1998; Quinn et al., 2004). These results contrast with those described in seawater environments, where a preferential LREE enrichment in the Fe oxides has been observed. Stable aqueous carbonate complexes with HREE formed in marine environments to prevent their adsorption (Koeppenkastrop and 
De Carlo, 1992; Kawabe et al., 1999b). In acid mine waters, however, sulfate complexes are the dominant aqueous species, while carbonate complexes are only relevant at $\mathrm{pH}$ values higher than 6.5 .
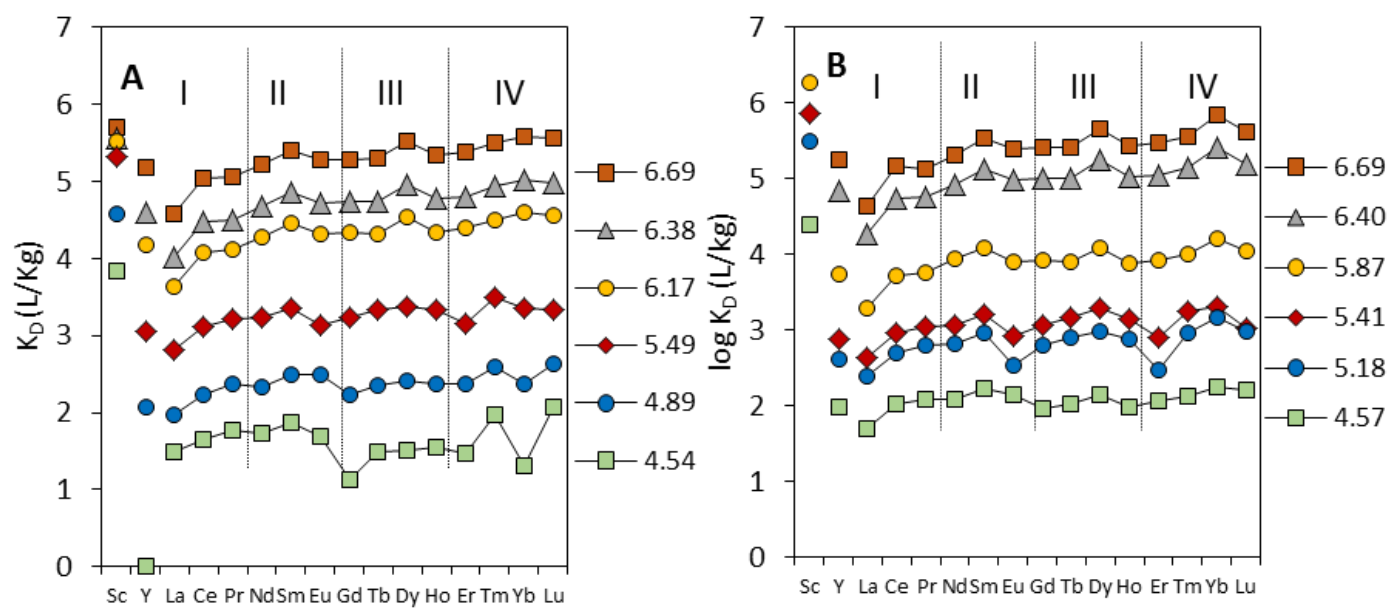

Fig. 2. Log $K_{D}$ values at different $\mathrm{pH}$ values showing the lanthanide M-type tetrad effect: $(A)$ solutions with $20 \mathrm{mM} \mathrm{SO}_{4} ; \mathrm{B}$ ) solutions with $2 \mathrm{mM} \mathrm{SO}_{4}$.

Bau (1999) observed an important positive Ce anomaly in hydrous ferric oxide precipitated with REE in the absence of sulfate that was attributed to the oxidation of $\mathrm{Ce}$ and the precipitation of $\mathrm{CeO}_{2}$. This anomaly was not observed in the present experiments (Fig. 2), nor was it observed by Verplanck et al. (2004) in the precipitates obtained after neutralizing acid mine waters with high sulfate concentrations. This observation suggests that sulfate may inhibit Ce oxidation due to sulfate complexation.

According to its ionic radius, $\mathrm{Y}$ is commonly displayed between Dy and $\mathrm{Ho}$, where it presents a negative anomaly (not shown in Fig. 2), as evidenced by the $K_{D}{ }^{Y} / K_{D}{ }^{D y}$ and $K_{D}{ }^{Y} / K_{D}{ }^{H o}$ ratios below unity (Table S6). The $Y$ anomalies in amorphous Fe(III)-hydroxides were attributed to covalent interactions with the Fe solids (Quinn et al., 2004). The negative $\mathrm{Gd}$ and $\mathrm{Yb}$ anomalies at lower $\mathrm{pH}$ values in the experimental set with $20 \mathrm{mM} \mathrm{SO}_{4}$ were not previously reported in the literature for similar experiments (Bau 1999; Quinn et al., 2006) and are attributed to analytical errors.

\section{Discussion}

\subsection{Model description}

In AMD environments, high sulfate concentrations are common, and dissolved sulfate strongly complexes with REE (Gimeno et al., 2000). An increase in sulfate concentration in solution leads to a higher proportion of sulfate complexes, which predominate for sulfate concentrations higher than $1 \mathrm{mM}$. Because $\mathrm{MSO}_{4}^{+}$is a predominant species in both experimental sets at 20 and $2 \mathrm{mM} \mathrm{SO}_{4}$, the sorption is similar, with only some differences between them. For the lanthanides and $\mathrm{Y}$, other aqueous complexes, such as $\mathrm{MOH}^{2+}, \mathrm{MCO}_{3}{ }^{+}$ and $\mathrm{M}\left(\mathrm{CO}_{3}\right)_{2}$, become important at low sulfate concentrations and $\mathrm{pH}$ values higher than 6.5 (Fig. 3A, B). Unlike $Y$ and the lanthanides, Sc hydrolysis complexes are stronger and play a 
significant role in $\mathrm{Sc}$ aqueous speciation at $\mathrm{pH}$ values higher than 4.6 (Fig. 3C, D). However, in contrast to the rest of the REE, carbonate complexes with Sc are not described due to the strong Sc affinity for hydrolysis products (Wood and Samson, 2006).
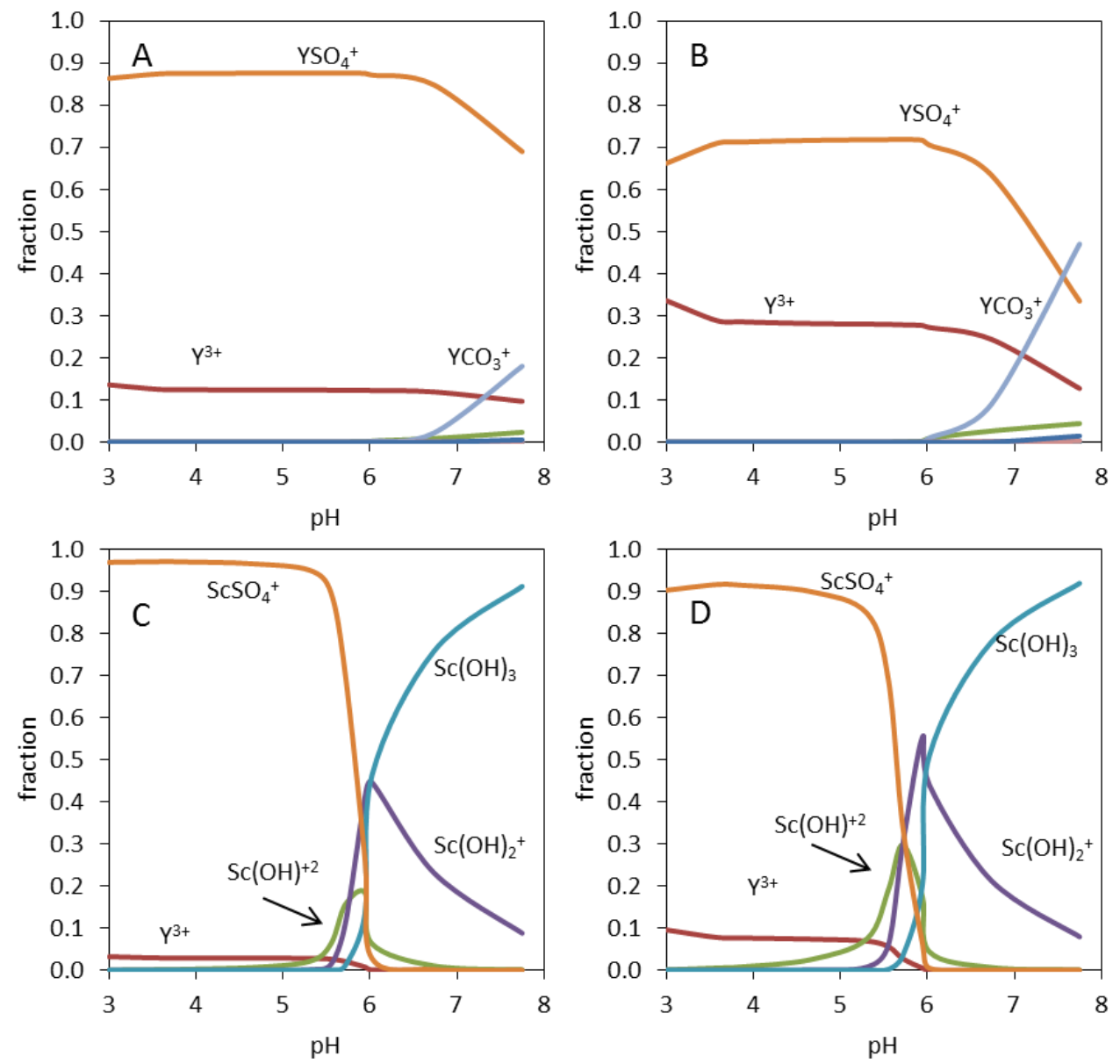

Fig. 3. Aqueous species distributions of $Y$ and $S c(0.01 \mathrm{mM})$ with different $\mathrm{pH}$ values in solutions of $20 \mathrm{mM}(\mathrm{A}, \mathrm{C})$ or $2 \mathrm{mM}(\mathrm{B}, \mathrm{D})$ sulfate at $25^{\circ} \mathrm{C}$ and atmospheric $\mathrm{CO}_{2}$ pressure.

Different surface complexation models have been commonly used to reproduce experimental REE sorption onto amorphous ferric hydroxide, hematite and goethite. Traditionally, REE sorption onto ferric, manganese and/or aluminum hydroxides/oxides has been explained by the process of free ion sorption onto mineral surface sites. Some models consider the electrostatic term, which accounts for the effect of surface charge on the sorption of free ions or hydrolysis products (Tochiyama et al., 1996; Rabung et al., 1998; Marmier et al., 1997; Marmier and Fromage, 1999; Quinn et al., 2006a). In contrast, a non-electrostatic model can be used when the chemical interaction of the adsorbed cations is stronger than the electrostatic forces present during sorption (Davis and Kent, 1990); therefore, the electrostatic term can be omitted. Here, a non-electrostatic model is proposed to describe REE sorption onto schwertmannite in an experimental setting. Similarly, some previous studies have proposed a non-electrostatic model to predict REE adsorption on basaltic rock (Tertre et al., 2008) and the sorption of $Y$ and the lanthanides onto amorphous iron hydroxides (Rabung et al., 2000; Quinn et al., 2006) and onto basaluminite (Lozano et al., 2019). 
Instead of developing a surface complexation model with free metal ions, the sorption of aqueous sulfate complex $\mathrm{MSO}_{4}{ }^{+}$is proposed because sulfate complexes are predominant in the synthetic solutions prepared for these experiments (Fig. 3). In contrast, REE-carbonate aqueous species were not considered because the proportion of carbonate species is very low in the $\mathrm{pH}$ range and sulfate concentrations used in the experiments.

The sorption reaction consists of the exchange of the $\mathrm{M}^{2+}$ aqueous complex, $\left(\mathrm{M}^{2+}\right.$ accounting for $\mathrm{MSO}_{4}^{+}$or $\mathrm{Sc}(\mathrm{OH})_{2}{ }^{+}$) with $\mathrm{n}$ protons from $\mathrm{n}$ surface sites $(\mathrm{XOH})$, reflecting the $\mathrm{pH}$ dependence observed in the experiments (section 3.2 ):

$\mathrm{M}^{\mathrm{z}+}+\mathrm{nXOH}=(\mathrm{XO})_{\mathrm{n}} \mathrm{M}^{\mathrm{z}-\mathrm{n}}+\mathrm{nH}^{+} \quad \mathrm{K}_{\mathrm{M}}$

The equilibrium constant, $K_{M}$, of the surface complexation reaction for each REE aqueous complex would be

$\mathrm{K}_{\mathrm{M}}=\frac{\left[(\mathrm{XO})_{\mathrm{n}} \mathrm{M}^{\mathrm{Z}-\mathrm{n}}\right] \cdot \mathrm{a}_{\mathrm{H}^{+}}^{\mathrm{n}}}{\mathrm{a}_{\mathrm{M}_{4}^{\mathrm{Z}}} \cdot[\mathrm{XOH}]^{\mathrm{n}}}$

where $\left[(X O)_{n} M^{\mathrm{Z}-\mathrm{n}}\right]$ and $[\mathrm{XOH}]$ account for the mole fractions of the sorbed species $\left(\left[(\mathrm{XO})_{n} \mathrm{M}^{\mathrm{z}^{-}}\right.\right.$ $\left.\left.{ }^{n}\right] /\left[T_{X O H}\right]\right)$ and of the free surface sites $\left([\mathrm{XOH}] / T_{\mathrm{XOH}}\right) ; \mathrm{a}_{\mathrm{M}_{4}^{z+}}$ and $\mathrm{a}_{\mathrm{H}^{+}}$represent the activities of the aqueous complex and proton, respectively. Considering the aqueous speciation described above, the total dissolved REE is assumed to be $\mathrm{MSO}_{4}{ }^{+}$. A total surface site concentration, $\mathrm{T}_{\mathrm{XOH}}$, of $1.367 \cdot 10^{-3} \mathrm{~mol} / \mathrm{L}$ was obtained from a schwertmannite site density of $4.7 \mathrm{sites} / \mathrm{nm}^{-2}$ (section 3.1) and a solid:liquid ratio of $1 \mathrm{~g} / \mathrm{L}$. The equilibrium constants expressed in this work are equivalent to those referred to as $K_{3}$ in model 3 proposed by Wang and Giammar (2013), where the surface mole fraction is proposed to better describe the mass action expression for bidentate sorption. The concentration of free surface sites was calculated as the difference between the total surface site concentration and total REE sorbed:

$[\mathrm{XOH}]=\mathrm{T}_{\mathrm{XOH}}-\sum \mathrm{n}\left[(\mathrm{XO})_{\mathrm{n}} \mathrm{M}^{\mathrm{z}-\mathrm{n}}\right]$

Data from the experiment with $20 \mathrm{mM} \mathrm{SO}_{4}$ were used to calculate the equilibrium constant. Thus, Eq. (4) was rearranged after taking logarithms, obtaining the linear expression shown in Eq. (6):

$\log \frac{\left[(\mathrm{XO})_{\mathrm{n}} \mathrm{M}^{\mathrm{z}-\mathrm{n}}\right]}{\mathrm{a}_{\mathrm{M}^{\mathrm{z}+}}}-\mathrm{n} \log [\mathrm{XOH}]+(\mathrm{n}-1) \log \mathrm{T}_{\mathrm{XOH}}=\mathrm{n} \mathrm{pH}+\log \mathrm{K}_{\mathrm{M}}$

The amount of occupied sites with sorbed REEs was lower than $10 \%$ in the higher $\mathrm{pH}$ experiments and was decreased for lower $\mathrm{pH}$ values. Therefore, the concentration of free sites $[\mathrm{XOH}]$ can be approximated to that of total sites, $\mathrm{T}_{\mathrm{XOH}}$, and Eq. (6) can be simplified:

$\log \frac{\left[(\mathrm{XO})_{\mathrm{n}} \mathrm{M}^{\mathrm{z}-\mathrm{n}}\right]}{\mathrm{a}_{\mathrm{M}^{\mathrm{z}}}}-\log \mathrm{T}_{\mathrm{XOH}}=\mathrm{npH}+\log \mathrm{K}_{\mathrm{M}}$

The experimental data were plotted according to Eq. (7), where the slope with respect to the $\mathrm{pH}$ indicated the denticity of the surface complex, and the equilibrium constant was obtained from the intercept. The slope varies from 1.4 to 2, increasing with decreasing ionic radius (Fig. 4). Therefore, bidentate surface complexes were assumed for simplicity, although a proportion 
of monodentate complexes may also be present. The equilibrium constants were obtained as the intercept of a straight line of slope 2 by fitting the experimental data set of $20 \mathrm{mM} \mathrm{SO}_{4}$, according to Eq. (7). Gnuplot v5.00 software (Williams and Kelley, 1986) was used for regression fitting. The error of the regression was larger and included the analytical error; therefore, it was assumed to be the error of the $\log K_{M}$ value.
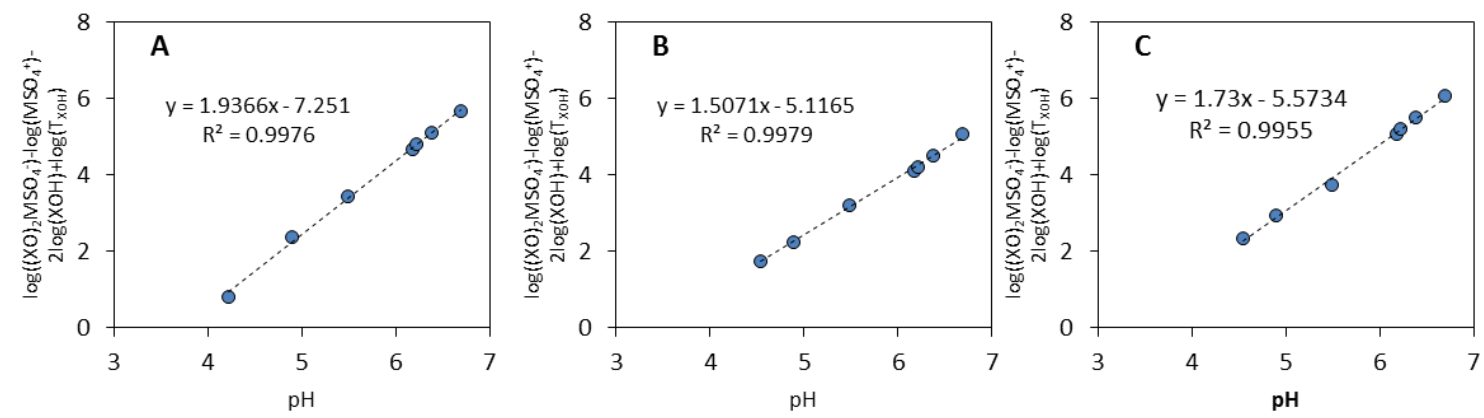

Fig. 4. Regressions obtained from measured $\mathrm{pH}$ values and calculated activities from the final concentrations of the experimental data set of $20 \mathrm{mM} \mathrm{SO}_{4}$. A, B, C) Regressions for $\mathrm{Y}, \mathrm{La}$ and Lu, respectively, plotted as Eq. (7).

Sc aqueous speciation showed that in addition to $\mathrm{ScSO}_{4}{ }^{+}$, the species $\mathrm{ScOH}^{2+}$ and $\mathrm{Sc}(\mathrm{OH})_{2}{ }^{+}$are also relevant in the $\mathrm{pH}$ range studied (Fig. 3C, D). The linear regression of Eq. (7) for $\mathrm{ScSO}_{4}{ }^{+}$ experimental data in sorption with high sulfate concentration showed a slope close to 2 (Fig. $5 \mathrm{~A})$. Although the $\mathrm{Sc}(\mathrm{OH})_{2}{ }^{+}$species became relevant from $\mathrm{pH} 5$, the correlation with $\mathrm{pH}$ was very poor (not shown), and it was not considered. In contrast, $\mathrm{ScOH}^{2+}$ showed a good linear regression, which resulted in a slope of 1.5 (Fig. 5B). Thus, similar to $\mathrm{Y}$ and to the lanthanides, $\mathrm{ScSO}_{4}{ }^{+}$and $\mathrm{ScOH}^{2+}$ were assumed to form bidentate surface complexes. Similar bidentate complexes were obtained by EXAFS fitting analysis of Lu sorbed onto ferrihydrite and Eu sorbed onto hematite (Dardenne et al., 2001; Estes et al., 2013). In contrast, REEs are found to form monodentate surface complexes in basaluminite (Lozano et al., 2019). Additionally, Rabung et al. (2006) obtained data showing that Lu formed monodentate surface complexes on $\mathrm{y}-\mathrm{Al}_{2} \mathrm{O}_{3}$ after fitting EXAFS spectra. This finding is probably because the Fe-O bond is longer than that of Al-O, providing more space to allocate bidentate surface complexes.
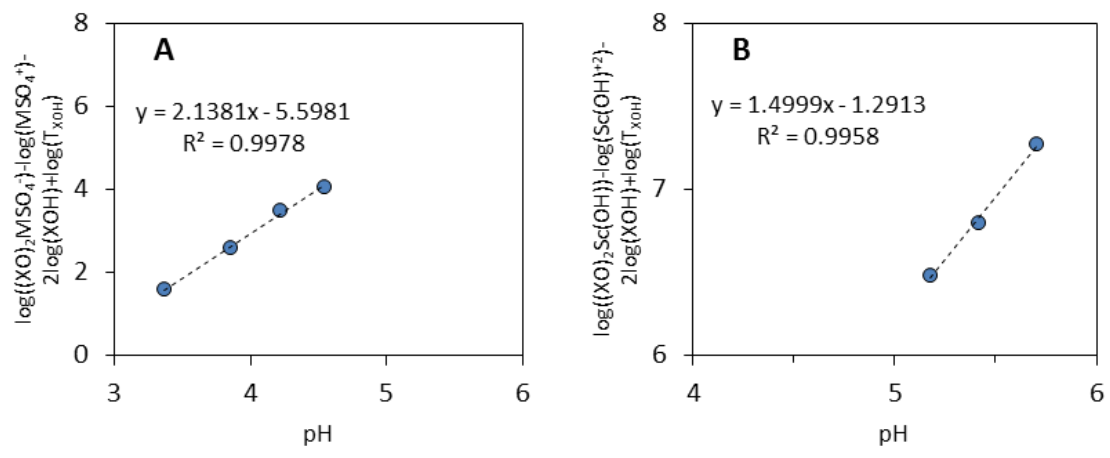

Fig. 5. Regressions obtained from experimental data of Sc plotted according to Eq. (7) for $\mathrm{ScSO}_{4}^{+}(\mathrm{A})$ and $\mathrm{ScOH}^{2+}(\mathrm{B})$ species. 
The calculated $\log \mathrm{K}_{\mathrm{M}}$ values with the errors for the bidentate surface complexation reactions are displayed in Table 1. Equilibrium constants increased from -7.96 to -7.13 from La to Lu, indicating the higher affinity of HREEs than LREEs for the schwertmannite surface.

Table 1. REE surface complexation constants for bidentate surface complexes obtained by fitting the experimental equation with a concentration of $20 \mathrm{mM} \mathrm{SO}_{4}$, surface site density of $4.7 \mathrm{~nm}^{-2}$, a specific surface area of $173 \mathrm{~m}^{2} / \mathrm{g}$ and a solid:liquid ratio of $1 \mathrm{~g} / \mathrm{L}$.

\begin{tabular}{|c|c|c|c|}
\hline Element & $\begin{array}{l}\text { Surface } \\
\text { complex }\end{array}$ & $\log K_{M}$ & Error \\
\hline \multirow[t]{2}{*}{ Sc } & $(\mathrm{XO})_{2} \mathrm{ScSO}_{4}{ }^{-}$ & -5.27 & 0.07 \\
\hline & $(\mathrm{XO})_{2} \mathrm{ScOH}$ & -3.4 & 0.08 \\
\hline Y & $(\mathrm{XO})_{2} \mathrm{YSO}^{-}$ & -7.62 & 0.04 \\
\hline La & $(\mathrm{XO})_{2} \mathrm{LaSO}^{-}$ & -7.96 & 0.15 \\
\hline $\mathrm{Ce}$ & $(\mathrm{XO})_{2} \mathrm{CeSO}_{4}^{-}$ & -7.60 & 0.10 \\
\hline $\operatorname{Pr}$ & $(\mathrm{XO})_{2} \mathrm{PrSO}^{-}$ & -7.52 & 0.13 \\
\hline $\mathrm{Nd}$ & $(\mathrm{XO})_{2} \mathrm{NdSO}_{4}^{-}$ & -7.44 & 0.09 \\
\hline Sm & $(\mathrm{XO})_{2} \mathrm{SmSO}^{-}$ & -7.27 & 0.08 \\
\hline $\mathrm{Eu}$ & $(\mathrm{XO})_{2} \mathrm{EuSO}^{-}$ & -7.41 & 0.09 \\
\hline Gd & $(\mathrm{XO})_{2} \mathrm{GdSO}^{-}$ & -7.51 & 0.05 \\
\hline $\mathrm{Tb}$ & $(\mathrm{XO})_{2} \mathrm{TbSO}^{-}$ & -7.42 & 0.06 \\
\hline Dy & $(\mathrm{XO})_{2} \mathrm{DySO}^{-}$ & -7.27 & 0.03 \\
\hline Ho & $(\mathrm{XO})_{2} \mathrm{HoSO}_{4}^{-}$ & -7.38 & 0.06 \\
\hline Er & $(\mathrm{XO})_{2} \mathrm{ErSO}_{4}^{-}$ & -7.39 & 0.05 \\
\hline $\mathrm{Tm}$ & $(\mathrm{XO})_{2} \mathrm{TmSO}^{-}$ & -7.17 & 0.08 \\
\hline $\mathrm{Yb}$ & $(\mathrm{XO})_{2} \mathrm{YbSO}^{-}$ & -7.26 & 0.04 \\
\hline Lu & $(\mathrm{XO})_{2} \mathrm{LuSO}^{-}$ & -7.13 & 0.09 \\
\hline
\end{tabular}

The sorption edge for each REE was calculated with the PHREEQC software. As expected, the calculations match the experimental data set of $20 \mathrm{mM} \mathrm{SO}_{4}$ (Fig. 6). The predicted and experimental sorption edges for the complete set of REE are shown in Fig. S5. With the exception of a slight overestimation for La, the model fit the concentration of the rest of the lanthanides and $Y$ within the experimental error (Fig. S5). Regarding Sc, the good fit observed between the model-predicted outcome and the measured from experiments confirmed the existence of two different surface species. This result highlights the different behavior of Sc sorption with respect to the rest of the REE onto schwertmannite and is a consequence of its different aqueous speciation. On the atomic scale, the Sc ionic radius is $0.75 \AA$ (Rudolph and Pye, 2000), which is considerably lower than that of Lu, the smallest radius of the lanthanide series $(0.98 \AA$ ) . 

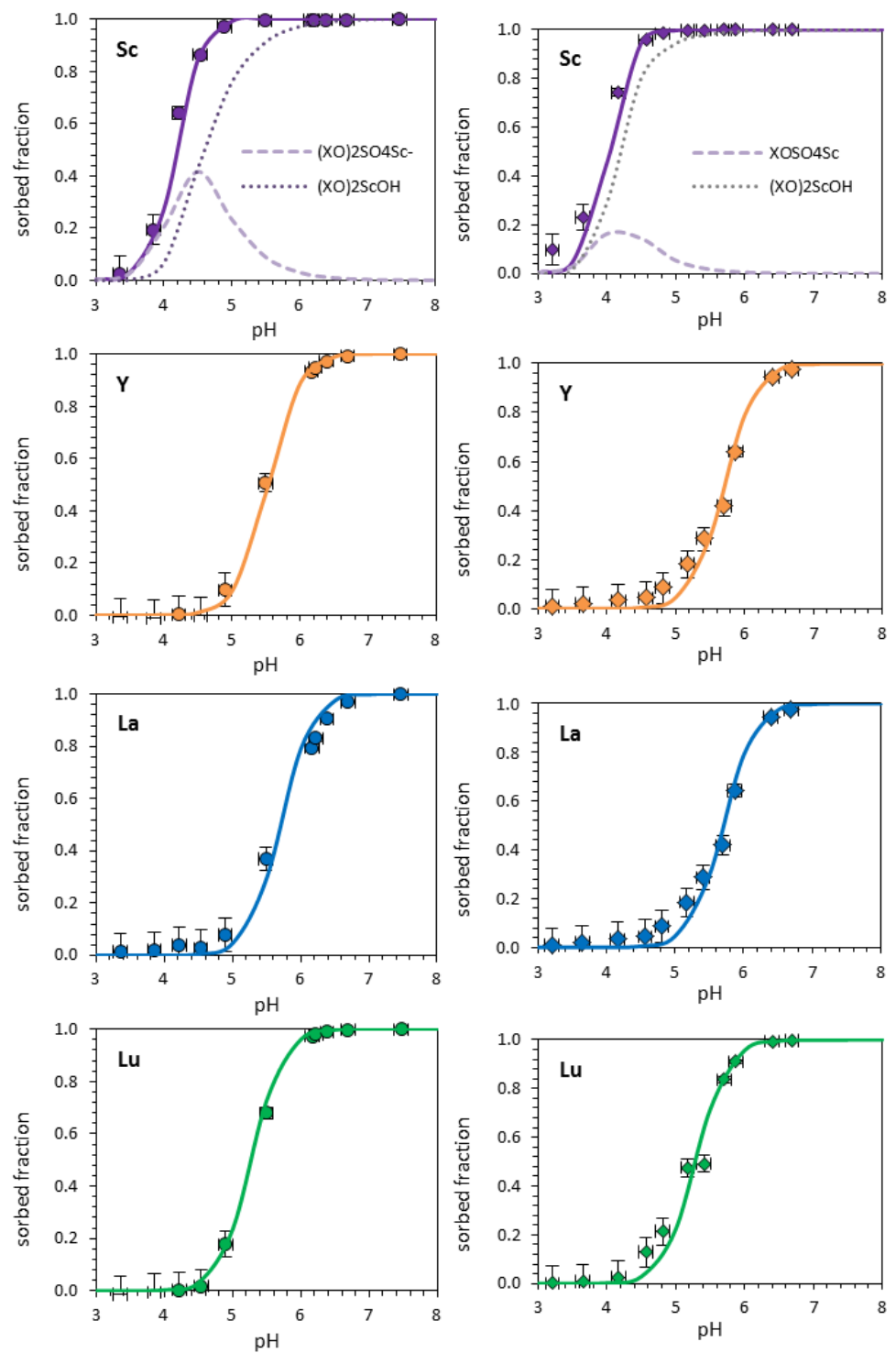

Fig. 6. Experimental (symbols) and calculated fractions (lines) of the sorption curves for Sc, $Y$, $\mathrm{La}$ and $\mathrm{Lu}$ for the experiments with $20 \mathrm{mM} \mathrm{SO}_{4}$ (left column) and with $2 \mathrm{mM} \mathrm{SO}_{4}$ (right column). Calculations at $25^{\circ} \mathrm{C}$ and atmospheric $\mathrm{CO}_{2}$ pressure.

\subsection{Model validation}

The model constructed with the $20 \mathrm{mM} \mathrm{SO}_{4}$ experimental data set was validated with three additional data sets: one set with $2 \mathrm{mM} \mathrm{SO}_{4}$ and a solid:liquid ratio of $1 \mathrm{~g} / \mathrm{L}$, and another two sets with $20 \mathrm{mM} \mathrm{SO}_{4}$ and solid:liquid ratios of $0.25 \mathrm{~g} / \mathrm{L}$ and $2 \mathrm{~g} / \mathrm{L}$, respectively.

The experimental and predicted values for $\mathrm{Y}, \mathrm{La}$, Lu and Sc for $2 \mathrm{mM} \mathrm{SO}_{4}$ and $1 \mathrm{~g} / \mathrm{L}$ solid:liquid ratio are plotted in Fig. 6 (right column). The predicted and experimental values for the complete set of REE are shown in Fig. S6. Although with a slight underestimation at lower pH values, the modeled curves match the experimental sorption at lower sulfate concentrations within the experimental error, confirming the formation of bidentate surface complexes.

The comparisons between the modeled and experimental data of selected elements for 1,2 and $0.25 \mathrm{~g} / \mathrm{L}$ solid:liquid ratios are shown in Fig. 7, and the data for the complete set of REE are 
plotted in Fig. S7. Despite a slight overprediction at higher $\mathrm{pH}$ values for the $0.25 \mathrm{~g} / \mathrm{L}$ solid:liquid ratio, the sorbed fractions for the different suspension concentrations were successfully predicted by the model within the experimental errors.
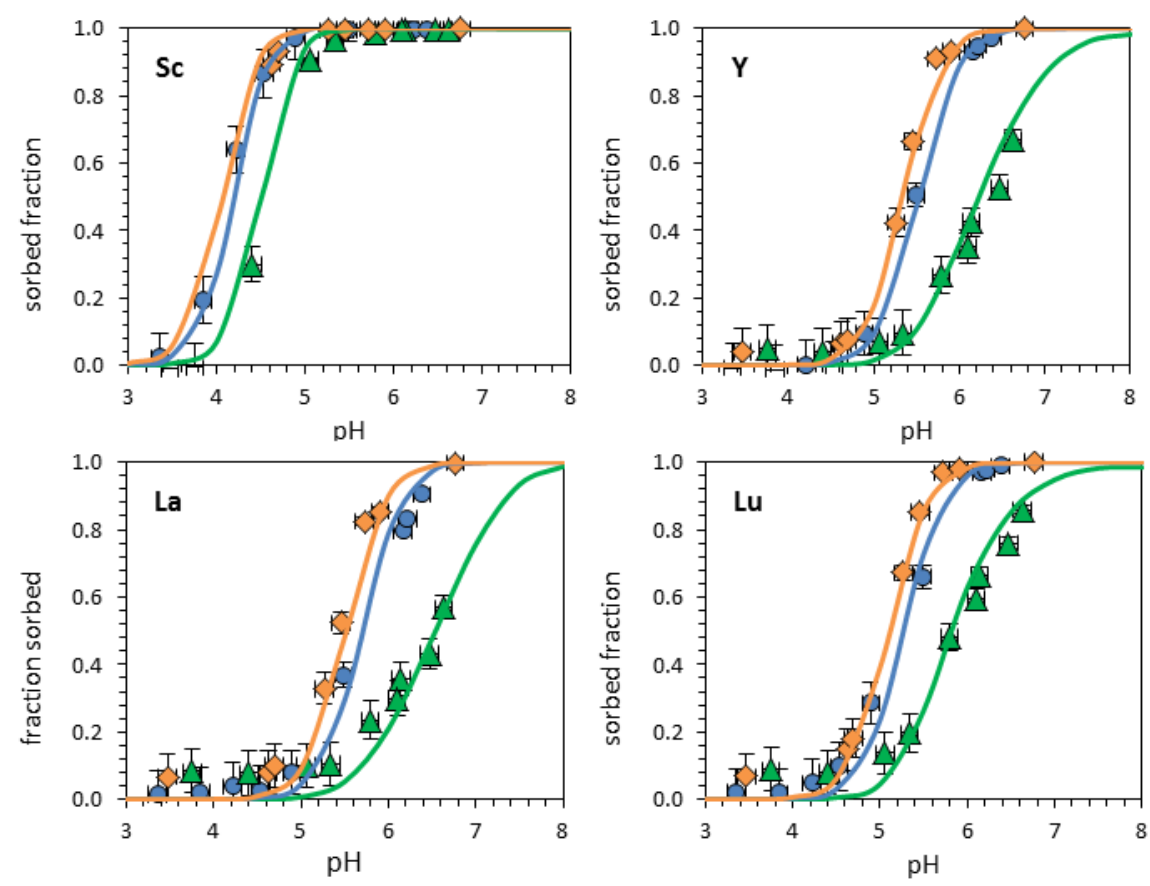

Fig. 7. Experimental data (symbols) and predicted sorbed fraction (lines) for sorption in $20 \mathrm{mM}$ $\mathrm{SO}_{4}$ in solution and solid:liquid ratios of $2 \mathrm{~g} / \mathrm{L}$ (orange diamonds), $1 \mathrm{~g} / \mathrm{L}$ (blue circles) and 0.25 $\mathrm{g} / \mathrm{L}$ (green triangles). Calculations at $25^{\circ} \mathrm{C}$ and atmospheric $\mathrm{CO}_{2}$ pressure.

\subsection{REE mobility in an AMD neutralization column}

The objective of the column experiment was to obtain a data set of the REE concentrations in the pore water and in the solid phases using a depth-time grid. Only Sc, La and Y were compared due to their different sorption-pH behaviors; additionally, La and $Y$ are representative of the LREE and HREE, respectively, and their analyzed values were always above the detection limits. The experimental data were compared with a 1D reactive transport model, including the REE sorption model on schwertmannite described above. 


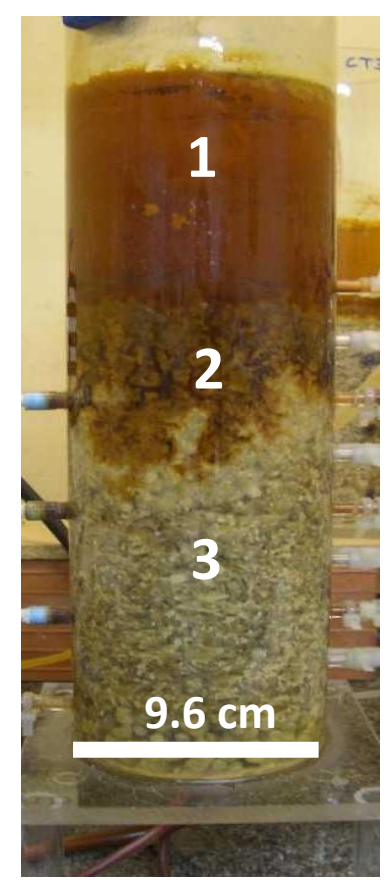

Fig. 8. View of the column after 28 days of the experiment: $1=$ supernatant AMD; $2=$ schwertmannite zone; $3=$ basaluminite+calcite zone.

The reactive transport model considered $0.25 \mathrm{~mol} / \mathrm{L}$ of calcite being dissolved by an inflow of AMD (Table S7). As the acid water infiltrates, calcite dissolves according to the kinetic law described by Plummer et al. (1978) and included in the database of the PHREEQC code. The reactive surface area was calibrated to $0.23 \mathrm{~m}^{2} / \mathrm{L}$ in order to fit the observed $\mathrm{pH}$ profiles. As $\mathrm{pH}$ rose, first schwertmannite and later basaluminite and gypsum precipitated under local equilibrium conditions. The results of the calculations for major solutes in pore water and the amount of mineral dissolved/precipitated are plotted in Fig. 9A-F. Essentially, for a given time the $\mathrm{pH}$ increased with depth, and for a given depth the column was progressively invaded by more acidic water. A schwertmannite front appeared first, at lower $\mathrm{pH}$ values $(\mathrm{pH} 2.5)$, followed by a basaluminite front $(\mathrm{pH}>3.8)$, with both fronts advancing with time. When calcite was exhausted, the acid water dissolved the basaluminite and the Al concentration in the pore water increased above the inflow concentration (Fig. 9C).

According to Fig. 6 and 7, lanthanides and $\mathrm{Y}$ only sorb at $\mathrm{pH}$ higher than 4 . Since schwertmannite only formed at lower $\mathrm{pH}$, sorption of these elements was only expected in basaluminite. Unlikely, Sc could also sorb in schwertmannite. The surface complexes and log $\mathrm{K}$ values described in Table 1 were used to describe the Sc sorption on schwertmannite, and those of Lozano et al. (2019) were used to calculate the lanthanide and $Y$ sorption onto basaluminite. As initial conditions, the number of sorption sites was deduced from the properties of schwertmannite $\left(4.7\right.$ sites $/ \mathrm{nm}^{2} ; 173 \mathrm{~m}^{2} / \mathrm{g}$, section 3.1 ) and basaluminite (4.6 sites $/ \mathrm{nm}^{2}, 68 \mathrm{~m}^{2} / \mathrm{g}$ according to Lozano et al., 2019). The solid/liquid ratio for both minerals was calculated from their total amount formed (Fig. 9D, E) distributed in the column, and assuming a bulk solid density of $1.3 \mathrm{~kg} / \mathrm{L}$ (including the wood shavings) and a porosity of 0.46 . 

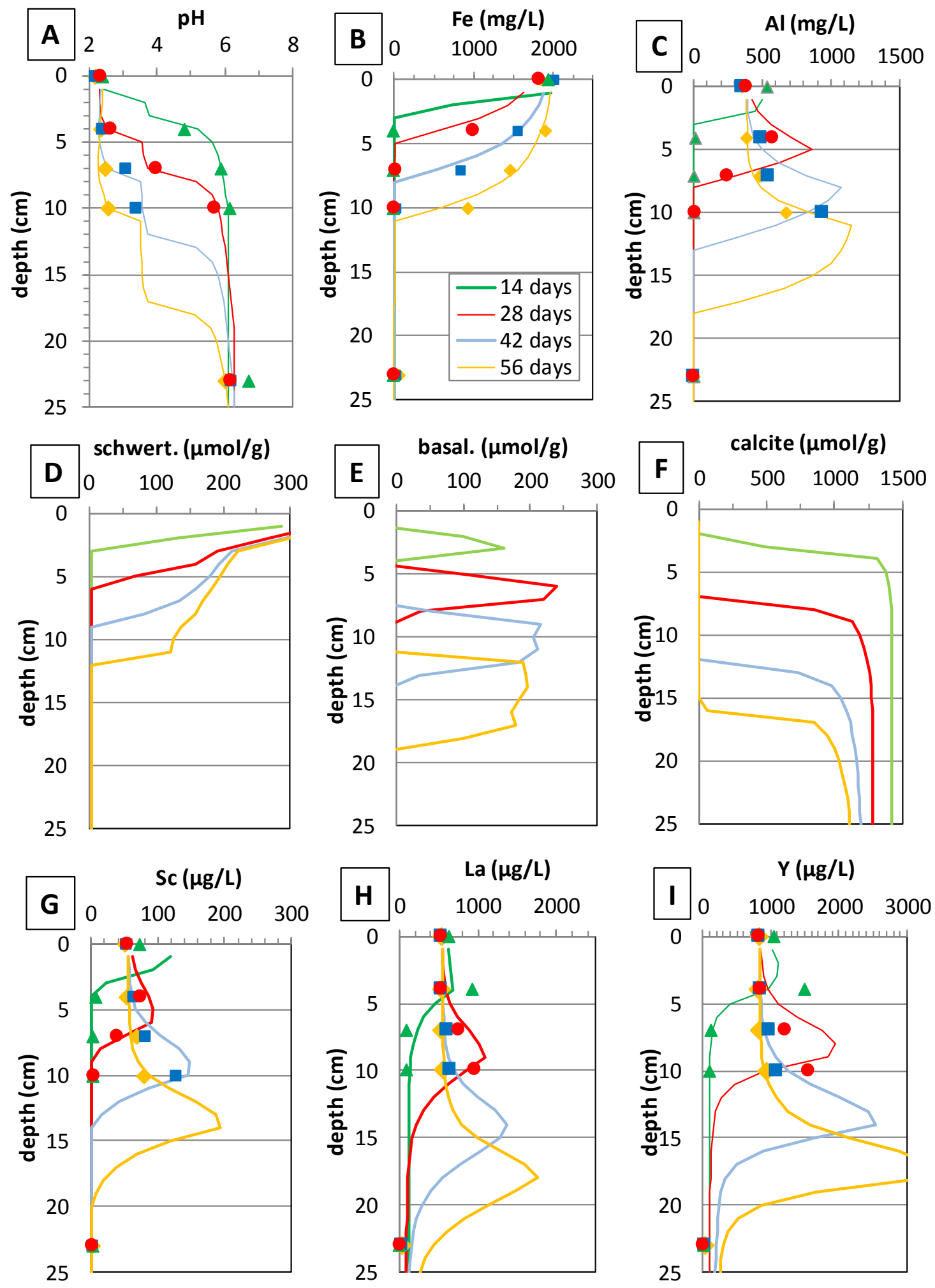

Fig. 9. Depth profiles of experimental data (symbols) and the reactive transport model (lines) at four different stages of column operation: A) pH evolution; B, C) Fe and Al concentrations in pore water; D, E, F) mineral distributions; $\mathrm{G}, \mathrm{H}, \mathrm{I}$ ) concentrations of selected REE in pore water. 
The differences in log $K$ values between $L a$ and $Y$ are small, and $L a$ and $Y$ yield a similar distribution in pore water. In contrast, the different behavior of Sc with respect to La and $Y$ is evident in both the measured and calculated pore water concentrations (Fig. $9 \mathrm{G}, \mathrm{H}, \mathrm{I}$ ). Thus, after two weeks, at $4 \mathrm{~cm}$ deep, the $\mathrm{pH}$ was 4.8 , and Sc was completely sorbed, whereas La and $\mathrm{Y}$, which had previously sorbed at an earlier time, were partially desorbing (notice their higher concentrations in the pore water than in the inflow). At $7 \mathrm{~cm}$, the pH increased to 5.9 , and the three REE remained sorbed. At deeper points, the $\mathrm{pH}$ was close to 6 , and again, the three REE were still sorbed. After four weeks and at $4 \mathrm{~cm}$ deep, the $\mathrm{pH}$ was 2.6, and Sc was desorbing, whereas $L a$ and $Y$ were already desorbed (their concentrations were equal to those in the inflow). At $7 \mathrm{~cm}$ deep, the $\mathrm{pH}$ was 4.1 , and Sc was partially sorbed, as demonstrated by its concentration being lower than that in the inflow, and La and $Y$ were desorbing, as shown again by their higher concentrations than those in the inflow. At $10 \mathrm{~cm}$ deep and with a pH of 5.7, Sc was entirely sorbed, whereas La and $Y$ were still partially desorbing. After six weeks and at $4 \mathrm{~cm}$ deep, the $\mathrm{pH}$ remained at 2.5, and all three REE were completely desorbed. Meanwhile, at 7 and $10 \mathrm{~cm}$ deep with a pH of 3.1 and 3.4, respectively, Sc was still desorbing, whereas La and $Y$ were practically desorbed. After 8 weeks, all three REE were desorbed at all recorded depths, with the exception of Sc, which was partially desorbed. At the end of the column ( $23 \mathrm{~cm}$ deep), the concentration of REE was very low throughout the experiment.

The column was dismantled after 58 days of functioning. The postmortem results of the column residue were in accordance with the mineral distribution predicted by the model. The presence of schwertmannite in the samples from the uppermost half of the column was marked by the amount of Fe recovered in steps II and III of the sequential extraction (Fig. 10). The presence of schwertmannite and minor goethite together with gypsum and residual calcite (data not presented) was confirmed by XRD. Although not identified on XRD due to its amorphous nature, the presence of basaluminite was evidenced by the amount of Al recovered in the second and third steps of the sequential extraction of samples of the lowermost half of the column. The presence of gypsum throughout the column was confirmed by the amount of $\mathrm{Ca}$ and $\mathrm{S}$ leached in extraction step I and the presence of calcite by the high amount of Ca present in extraction step II (data not presented). This solid phase distribution along the column is identical to that observed in other column experiments (Rötting et al., 2008a; Ayora et al., 2016) and those in two field scale treatments (Rötting et al., 2008b; Caraballo et al., 2009, 2011).

As evidenced in Fig. 10, a minor proportion of Sc and the rest of the REE was found in watersoluble step I, most likely linked to gypsum (Lin et al., 2019). However, most REE were found in steps II and III, which are representative of schwertmannite and basaluminite. However, some differences are evident in the depth distribution of Sc and the rest of the REE. More than $95 \%$ of the lanthanides and $Y$ ( $\Sigma R E Y$ ) match the Al distribution along the column depth, indicating that they are linked to basaluminite, as found in previous experiments (Ayora et al., 2016). However, up to $25 \%$ Sc was located in the first $6 \mathrm{~cm}$ of the column, matching the $\mathrm{Fe}$ distribution, and these results can be attributed to sorption on schwertmannite. According to the calculations, the $\mathrm{pH}$ value in the uppermost $10 \mathrm{~cm}$ was 2.5 , predicting a complete desorption for $\mathrm{La}$ and $\mathrm{Y}$ and almost complete desorption for Sc. Therefore, the remaining REEs, and particularly Sc, analyzed in the upper $10 \mathrm{~cm}$ of solid residue indicate that desorption was 
not entirely reversible. Indeed, desorption has also been reported to be a very slow process in experiments of Yb sorption on hematite and alumina (Marmier et al., 1997).
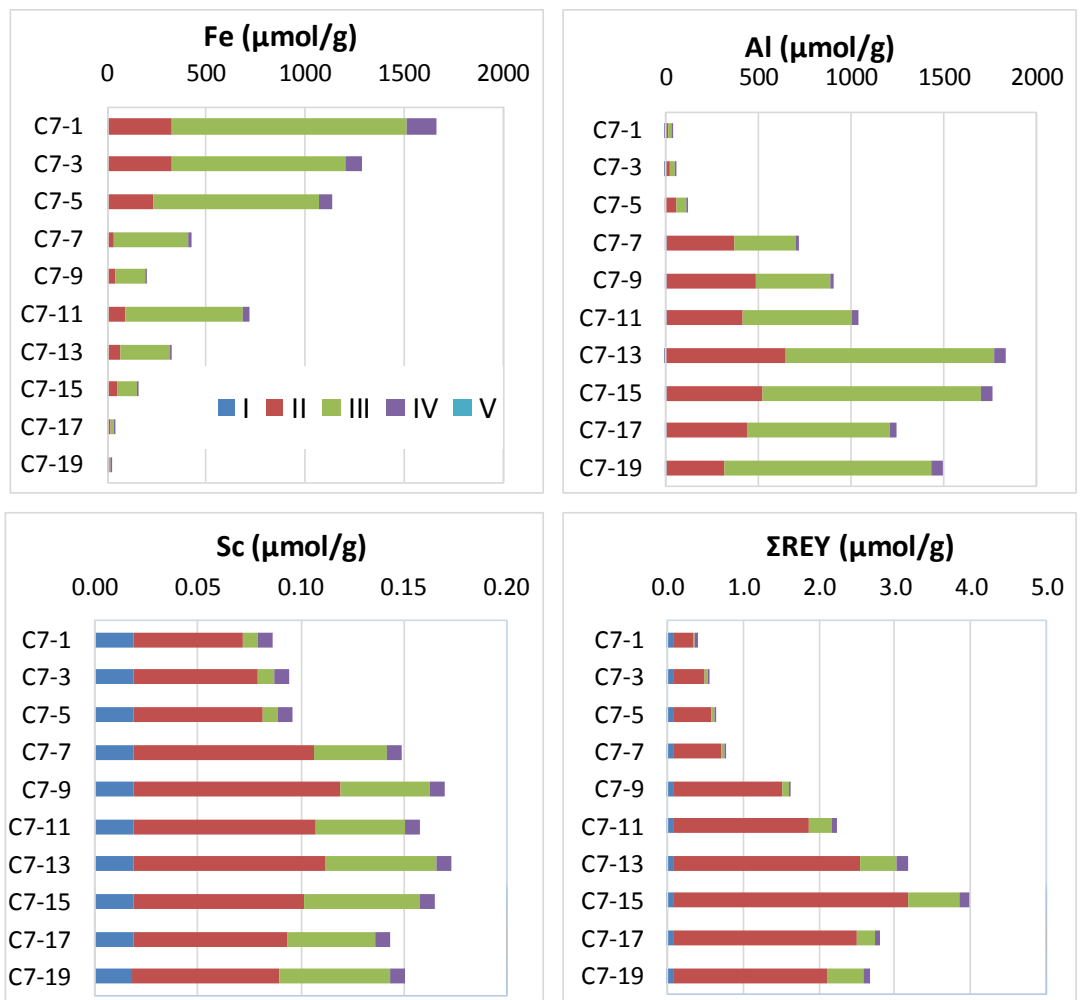

Fig. 10. Distribution of Fe, Sc, Al and $\sum$ REY (except Sc) concentration in the solid phase. The numbers on the vertical axes indicate the depth $(\mathrm{cm})$ in the column, and the colors indicate the different steps of sequential extraction (see text).

\section{Conclusions}

The experimental results confirm that the sorption of REE onto schwertmannite is highly dependent on $\mathrm{pH}$. For a solid:liquid ratio of $1 \mathrm{~g} / \mathrm{L}$, the sorption of the lanthanide series and $\mathrm{Y}$ is

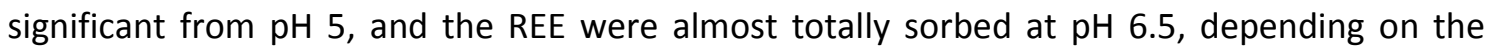
element. In contrast, the sorption of $Y$ and the lanthanides were not affected by the amount of sulfate in solution, probably because $\mathrm{MSO}_{4}{ }^{+}$is the overwhelming aqueous species above $1 \mathrm{mM}$ $\mathrm{SO}_{4}$. Similar to other iron and aluminum oxides/hydroxides, preferential sorption was observed from La to Lu. Very differently, Sc sorption starts at $\mathrm{pH} 4.5$, and more than $95 \%$ is retained at $\mathrm{pH}$ 5. The different behavior of Sc is explained by the adsorption of $\mathrm{ScOH}^{2+}$ in addition to $\mathrm{ScSO}_{4}{ }^{+}$. Due to the higher importance of the hydrolyzed species, Sc sorption slightly decreased as the concentration of sulfate in solution increased.

The results of the sorption experiments can be explained by a non-electrostatic model in which $\mathrm{MSO}_{4}^{+}$(and $\mathrm{ScOH}^{2+}$ ) exchanges with two surface protons, forming a bidentate surface complex. The value of the equilibrium constants of the surface complexation reactions were deduced from suspensions of $1 \mathrm{~g} / \mathrm{L}$ schwertmannite in a solution with $20 \mathrm{mM} \mathrm{SO}_{4}$, and these constants were successfully applied to describe experiments with $2 \mathrm{mM} \mathrm{SO}_{4}$ and with solid:liquid ratios of 2 and $0.25 \mathrm{~g} / \mathrm{L}$. 
The sorption model has been applied to describe the REE behavior in a column simulating a passive AMD remediation system. As AMD infiltrates the column, calcite dissolves and schwertmannite precipitates. The progression of neutralization raises the $\mathrm{pH}$ above 4 , and basaluminite forms. As a result, two fronts are formed: basaluminite progressing at a higher $\mathrm{pH}$ on the limestone column and schwertmannite behind, progressing at lower $\mathrm{pH}$ values. The model successfully predicts the analyses of REE in pore water and solid phases. Both the experiments and the model show different behaviors of Sc observed in the sorption experiments. Although schwertmannite and basaluminite have similar sorption edges, $Y$ and the lanthanides only sorb at $\mathrm{pH}$ values higher than 4.5 , and sorption only occurs on basaluminite because schwertmannite forms at $\mathrm{pH}$ values lower than 4 . In contrast, the Sc sorption edge extends from $\mathrm{pH} 3$ to 5 and therefore can partially sorb on schwertmannite. As a practical consequence, REE preferentially accumulate in the basaluminite residue of AMD neutralization systems. However, a minor but significant fraction of Sc can also be found in the schwertmannite sludge. 


\section{Acknowledgments}

This work was funded by the European EIT-Raw materials 'Morecovery' and the Spanish SCYRE (CGL2016-78783-C2-R)] projects. A. L. was also funded by the FPI grant (BES-2014-069978) from the Ministry of Science, Innovation and Universities (Spain). The authors thank J. Bellés, M. Cabañas, R. Bartrolí and N. Moreno (IDAEA-CSIC) for their analytical assistance.

\section{References}

Acero P., Ayora C., Torrentó C. and Nieto J. M. (2006) The behaviour of trace elements during schwertmannite precipitation and subsequent transformation into goethite and jarosite. Geochim. Cosmochim. Acta 70, 4130-4139.

Ackman T. (1982) Sludge disposal from acid mine drainage treatment. Report of Investigation 8672. US Bureau of Mines, Pittsburgh.

Antelo J., Fiol S., Gondar D., López R. and Arce F. (2012) Comparison of arsenate, chromate and molybdate binding on schwertmannite: Surface adsorption vs anion-exchange: J. Colloid Interface Sci. 386, 338-343.

Ayora C., Caraballo M. A., Macías F., Rötting T. S., Carrera J. and Nieto J. M. (2013). Acid mine drainage in the Iberian Pyrite Belt: 2. Lessons learned from recent passive remediation experiences. Environ. Sci. Pollut. R. 20, 7837-7853.

Ayora C., Macías F., Torres E., Lozano A., Carrero S., Nieto J. M., Pérez-López R. FernándezMartínez A. and Castillo-Michel H. (2016) Recovery of Rare Earth Elements and Yttrium from Passive-Remediation Systems of Acid Mine Drainage. Environ. Sci. Technol. 50 (15), 8255-8262.

Bau M., Koschinsky A., Dulski P., and Hein J. R. (1996) Comparison of the partitioning behaviours of yttrium, rare earth elements, and titanium between hydrogenetic marine ferromanganese crusts and seawater. Geochim. Cosmochim. Acta 60, 1709-1725.

Bau M. (1999) Scavenging of dissolved yttrium and rare earths by precipitating iron oxyhydroxide: experimental evidence for Ce oxidation, $\mathrm{Y}-\mathrm{Ho}$ fractionation, and lanthanide tetrad effect. Geochim. Cosmochim. Acta 63, 67-77.

Blanc PH, Lassin A. Piantone P., Azaroual M., Jacquement N., Fabbri A. and Gaucher E. C. (2012) Thermoddem: A geochemical database focused on low temperature water/rock interactions and waste materials. Appl. Geochem. 27, 2017-2216. 
Burton E. D., Bush R. T., Johnston S. G., Watling K. M., Hocking R. K., Sullivan L. A. and Parker G. K., (2009) Sorption of arsenic(V) and arsenic(III) to schwertmannite: Environ. Sci. Technol. 43, 9202-9207.

Byrne R. H. and Kim K. H. (1990) Rare earth element scavenging in seawater. Geochim. Cosmochim. Acta 54, 2645-2656.

Byrne R. H. and Sholkovitz E. R. (1996) Marine Chemistry and Geochemistry of the Lanthanides. Handb. Phys. Chem. Rare Earths 23, 497-593.

Caraballo M. A., Rötting T. S., Nieto J. M. and Ayora C. (2009) Sequential extraction and DRXD applicability to poorly crystalline Fe- and Al-phase characterization from an acid mine water passive remediation system. Am. Mineral. 94, 1029-1038.

Caraballo M. A., Macías F., Castillo J., Quispe D., Nieto J. M. and Ayora C. (2011) Hydrochemical performance and mineralogical evolution of a dispersed alkaline substrate (DAS) remediating the highly polluted acid mine drainage in the full scale passive treatment of Mina Esperanza (SW, Spain). Am. Mineral. 96, 1270-1277.

Cornell R. M. and Schwertmann U. (1996) The Iron Oxides: Structure, Properties, Reactions, Occurence and Uses. VCH Verlagsgesellschaft mbH, Weinheim.

Coulton R., Bullen C. and Hallet C. (2003) The design and optimization of active mine water treatment plants. Land Contam Reclam. 11, 273-279

Dardenne B. K., Schäfer T., Denecke M. A., Rothe J. and Kim J. I. (2001) Identification and Characterization of Sorbed Lutetium Species on 2-Line Ferrihydrite by Sorption Data Modeling, TRLFS and EXAFS. Radiochim. Acta 89, 469-479.

Davis J. A. and Kent D. B. (1990) Surface Complexation Modeling in Aqueous Geochemistry. Rev. Mineral. Geochem. 23, 177-260.De Carlo E. H., Wen X. and Irving M. (1998) The influence of redox reactions on the uptake of dissolved Ce by suspended Fe and $\mathrm{Mn}$ oxide particles. Aquat. Geochem. 3, 357-389

Elderfield H., Upstill-Goddard R. and Sholkovitz E. R. (1990) The rare earth elements in rivers, estuaries, and coastal seas and their significance to the composition of ocean waters. Geochim. Cosmochim. Acta 54, 971-991. 
Estes S. L., Arai Y., Becker U., Fernando S., Yuan K., Ewing R. C., Zhang J., Shibata T. and Powell B. A. (2013) A Self-Consistent Model Describing the Thermodynamics of Eu(III) Adsorption onto Hematite. Geochim. Cosmochim. Acta 122, 430-447.

Evangelou V.P. and Zhang Y. L. (1995) A review: Pyrite oxidation mechanisms and acid mine drainage prevention, Crit. Rev. Environ. Sci. Technol. 25:2, 141-199.

Fernández-Martínez A., Timon V., Romaman-Ross G., Cuello G. J., Daniels J. E. and Ayora C. (2010) The Structure of Schwertmannite, a Nanocrystalline Iron Oxyhydroxysulfate. Am. Mineral. 95 (8-9), 1312-1322.

Ferreira da Silva E., Ferreir, E., Bobos I, Matos J., Patinha C., Reis A. P. and Fonseca E. C. (2009) Mineralogy and geochemistry of trace metals and REE in massive volcanic sulphide host rocks, stream sediments, stream waters and acid mine drainage from the Lousal mine area (Iberian Pyrite Belt, Portugal). Appl. Geochem. 24, 383-401.

Fukushi K., Sato T., Yanase N., Minato J. and Yamada H. (2004) Arsenate Sorption on Schwertmannite. Am. Mineral. 89 (11-12), 1728-1734.

Gammons C. H., Wood S. A. and Nimick D. A. (2005a) Diel Behavior of Rare Earth Elements in a Mountain Stream with Acidic to Neutral PH. Geochim. Cosmochim. Acta 69 (15), 3747-3758.

Gammons C. H., Wood S. A., Pedrozo F., Varekamp J. C., Nelson B. J., Shope C. L. and Baffico G. (2005b) Hydrogeochemistry and rare earth element behavior in a volcanically acidified watershed in Patagonia, Argentina. Chem. Geol. 222, 249-267.

Gimeno M.J., Auque L.F. and Nordstrom D.K. (2000) REE speciation in low-temperature acidic waters and the competitive effects of aluminum. Chem. Geol. 165, 167-180.

Hatch G. P. (2012) Dynamics in the Global Market for Rare Earths. Elements, 8 (5), 341-346.

Hedin R. S., Watzlaf G. R.and Nairn R.W. (1994) Passive treatment of acid mine drainage with limestone. J. Environ. Qual. 23, 1338-1345.

Henderson P. (1984) General Geochemical Properties and Abundances of the Rare Earth Elements. In Developments in Geochemistry; Henderson, P., Ed. Vol. 2, pp 1-32. 
Johannesson K. H. and Lyons W. B. (1995) Rare-earth element geochemistry of Colour Lake, an acidic freshwater lake on Axel Heiberg Island, Northwest Territories, Canada. Chem. Geol. 119, 209-223.

Johnson J.W., Oelkers E.R., Helgeson H.C. (1992) SUPCRT92: A SOFTWARE PACKAGE FOR CALCULATING THE STANDARD MOLAL THERMODYNAMIC PROPERTIES OF MINERALS, GASES, AQUEOUS SPECIES, AND REACTIONS FROM 1 TO 5000 BAR AND 0 TO $1000^{\circ} \mathrm{C}$. Computers and Geosciences 18 (7), 899-947.

Kawabe I., Ohta A., Ishii S., Tokumura M. and Miyauchi K., (1999a) REE partitioning between $\mathrm{Fe}-\mathrm{Mn}$ oxyhydroxide precipitates and weaklyacid $\mathrm{NaCl}$ solutions: convex tetrad effect and fractionation of $Y$ and Sc from heavy lanthanides. Geochem. J. 33, 167-179.

Kawabe I., Ohta A. and Miura N. (1999b) Distribution coefficients of REE between Fe oxyhydroxide precipitates and $\mathrm{NaCl}$ solutions affected by REE-carbonate complexation. Geochem. J. 33 (3), 181-197.

Klungness G. D. and Byrne R. H. (2000) Comparative hydrolysis behavior of the rare earths and yttrium: the influence of temperature and ionic strength. Polyhedron 19, 99-107.

Koeppenkastrop D. and De Carlo E.H. (1992). Sorption of rare-earth elements from seawater onto synthetic mineral particles: an experimental approach. Chem. Geol. 95, 251-263.Lin J., Nilges M.J., Wiens E., Chen N., Wang S. and Pan Y. (2019) Mechanism of $\mathrm{Gd}^{3+}$ uptake in gypsum $\left(\mathrm{CaSO}_{4} \cdot 2 \mathrm{H}_{2} \mathrm{O}\right)$ : implications for EPR dating, REE recovery and REE behavior. Geochim. Cosmochim. Acta. https://doi.org/10.1016/j.gca.2019.05.019 GCA

Liu H., Pourret O., Guo H. and Bonhoure J., (2017). Rare earth elements sorption to iron oxyhydroxide: model development and application to groundwater. Appl. Geochem. 87, 158166.

Lozano A., Fernández-Martínez A. and Ayora A. (2019) Sorption of rare earth elements onto basaluminite: The role of sulfate and pH. Geochim. Cosmochim. Acta 258, 50-62.

Luo Y. R. and Byrne R. H. (2001) Yttrium and rare earth element complexation by chloride ions at 25 degrees. J. Solution Chem. 30 (9), 837-845.

Luo Y.R. and Byrne R.H., (2004). Carbonate complexation of yttrium and the rare earth elements in natural rivers. Geochim. Cosmochim. Acta 68, 691-699. 
Luo Y. and Millero F.J. (2004). Effects of temperature and ionic strength on the stabilities of the first and second fluoride complexes of yttrium and the rare earth elements. Geochim. Cosmochim. Acta 68 (21), 4301-4308.

Marmier N., Dumonceau A. J. and Fromage F. (1997) Surface complexation modeling of Yb(III) sorption and desorption on hematite and alumina. J. Contam. Hydrol. 26, 159-167.

Marmier N. and Fromage F. (1999) Comparing electrostatic and non-electrostatic surface complexation modeling of the sorption of lanthanum on hematite. J. Colloid Interf. Sci. 212, 252-263.

Massari S. and Ruberti M. (2013) Rare Earth Elements as Critical Raw Materials: Focus on International Markets and Future Strategies. Resour. Policy 38, 36-43.

Masuda A., Kawakami O., Dohmoto Y. and Takenaka T. (1987). Lanthanide tetrad effects in nature: two mutually opposite types, W and M. Geochem. J. 21, 119-124Millero F. J. (1992) Stability constants for the formation of rare earth inorganic complexes as a function of ionic strength. Geochim. Cosmochim. Acta 56, 3123-3132.

Noack C. W., Dzombak D. A. and Karamalidis A. K. (2014) Rare earth element distributions and trends in natural waters with a focus on groundwater. Environ. Sci. Technol. 48, 4317-4326.

Nordstrom D. K. (2011) Hydrogeochemical Processes Governing the Origin, Transport and Fate of Major and Trace Elements from Mine Wastes and Mineralized Rock to Surface Waters. Appl. Geochem. 26, 1777-1791.

Nordstrom D. K., Blowes D. W.and Ptacek C. J. (2015) Hydrogeochemistry and Microbiology of Mine Drainage: An Update. Appl. Geochem. 57, 3-16.

Ohta A. and Kawabe I. (2000a) Rare earth element partitioning between Fe oxyhydroxide precipitates and aqueous $\mathrm{NaCl}$ solutions doped with $\mathrm{NaHCO}_{3}$ : Determinations of rare earth element complexation constants with carbonate ions. Geochem. J. 34, 439-454.

Ohta A. and Kawabe I. (2000b) Theoretical study of tetrad effects observed in REE distribution coefficients between marine Fe- Mn deposit and deep seawater, and in REE(III)-carbonate complexation constants. Geochem. J. 34, 455-473.

Ohta A. and Kawabe I. (2001) REE(III) adsorption onto Mn dioxide ( $\delta$-MnO2) and Fe oxyhydroxide: $\mathrm{Ce}(\mathrm{III})$ oxidation by $\delta-\mathrm{MnO}_{2}$. Geochim. Cosmochim. Acta 65, 695-703. 
Parkhurst D. L. and Appelo C. A. J. (1999) User's guide to PhreeqC (version 2.18) A computer program for speciation, and inverse geochemical calculations, U.S. Department of the Interior, U.S. Geological Survey.

Plummer L. N, Parkhurst D. L., L., Wigley T. M. (1979) Critical Review of the Kinetics of Calcite Dissolution and Precipitation. In Chemical Modeling in Aqueous Systems (ed. E. Jenne) pp 537573. Am. Chem. Soc. Symp. Ser https://doi.org/10.1021/bk-1979-0093.ch025.

Quinn K. A., Byrne R. H. and Schijf J. (2004) Comparative scavenging of yttrium and the rare earth elements in seawater: competitive influences of solution and surface chemistry. Aquat. Geochem. 10, 59-80.

Quinn K. A., Byrne R. H. and Schijf J. (2006a) Sorption of yttrium and rare earth elements by amorphous ferric hydroxide: influence of pH and ionic strength. Mar. Chem. 99, 128-150.

Quinn K. A., Byrne R. H. and Schijf J. (2006b) Sorption of yttrium and rare earth elements by amorphous ferric hydroxide: influence of solution complexation with carbonate. Geochim. Cosmochim. Acta 70, 4151-4165.

Rabung T., Geckeis H., Jim J. I. and Beck H. P. (1998) Sorption of Eu(III) on natural hematite: application of surface complexation model. J. Coll. Interf. Sci. 208, 153-161.

Rabung Th., Stumpf Th., Geckeis H., Klenze R. and Kim J. I. (2000) Sorption of Am(III) and $\mathrm{Eu}(\mathrm{III})$ onto $\mathrm{Y}$-alumina: experiment and modeling. Radiochim. Acta 88, 711-716.

Ramasamy D. L., Puhakka V., Repo E., Ben Hammouda S. and Sillanpää M. (2018) Two-Stage selective recovery process of scandium from the group of rare earth elements in aqueous systems using activated carbon and silica composites: Dual applications by tailoring the ligand grafting approach. Chem. Eng. J. 341, 351-360.

Regenspurg S., Brand, A. and Peiffer S. (2004) Formation and Stability of Schwertmannite in Acidic Mining Lakes. Geochim. Cosmochim. Acta, 68 (6), 1185-1197.

Regenspurg S., and Peiffer, S. (2005). Arsenate and chromate incorporation in schwertmannite. Applied Geochemistry, 20 (6), 1226-1239.

Rötting T. S., Thomas R. C., Ayora C. and Carrera J. (2008a) Passive Treatment of Acid Mine Drainage with High Metal Concentrations Using Dispersed Alkaline Substrate. J. Environ. Qual. 37(5), 1741-1751. 
Rötting T. S, Caraballo MA, Serrano J. A., Ayora C. and Carrera J. (2008b) Field application of calcite Dispersed Alkaline Substrate (calcite-DAS) for passive treatment of acid mine drainage with high Al and metal concentrations. Appl. Geochem. 23, 1660-1674.

Rudolph W. W. and Pye C. C. (2000) Raman Spectroscopic Measurements of Scandium(III) Hydration in Aqueous Perchlorate Solution and ab Initio Molecular Orbital Studies of Scandium(III) Water Clusters: Does Sc(III) Occur as a Hexaaqua Complex? J. Phys. Chem. 104, 1627-1639.

Schijf J. and Byrne R. H. (2004) Determination of SO4ß1 for yttrium and the rare earth elements at $\mathrm{I}=0.66 \mathrm{~m}$ and $\mathrm{t}=25^{\circ} \mathrm{C}$-Implications for YREE solution speciation in sulfate-rich waters. Geochim. Cosmochim. Acta 68 (13) 2825-2837.

Schwertmann U. and Carlson L. (2005) The pH-dependent transformation of schwertmannite to goethite at 25 C. Clay Miner. 40, 63-66.

Sholkovitz E.R. (1995) The aquatic chemistry of rare earth elements in rivers and estuaries. Aquat. Geochem. 1, 1-34.

Spahiu K. and Bruno J. (1995) A selected thermodynamic database for REE to be used in HLNW performance assessment exercises. SKB Technical Report, 95-35, 88 pp.

Tertre E., Hofmann A. and Berger G. (2008) Rare earth element sorption by basaltic rock: Experimental data and modeling results using the "Generalised Composite Approach." Geochim. Cosmochim. Acta 72 (4), 1043-1056.

Torres E. and Auleda M. A (2013) Sequential Extraction Procedure for Sediments Affected by Acid Mine Drainage. J. Geochemical Explor. 128, 35-41.

Verplanck P. L., Antweiler R. C., Nordstrom D. K., Taylor H. E. (2001) Standard reference water samples for rare earth element determinations. Appl. Geochem. 16, 231-244.

Verplanck P. L., Nordstrom D. K., Taylor H. E. and Kimball B. A. (2004) Rare earth element partitioning between hydrous ferric oxides and acid mine water during iron oxidation. Appl. Geochem. 19, 1339- 1354.

Viadero Jr., R. C., Wei X. and Buzby K. M. (2006) Characterization and dewatering evaluation of acid mine drainage sludge from ammonia neutralization. Environ. Eng. Sci. 23 (4), 734-743. 
Wang Z. and Giammar D. E. (2013) Mass action expressions for bidentate adsorption in surface complexation modeling: Theory and practice. Environ. Sci. Technol. 47(9), 3982-3996.

Williams T and Kelley C. (1986) An interactive Plotting Program.

Wood S. A. and Samson A. M. (2006). The aqueous geochemistry of gallium, germanium, indium and scandium. Ore Geol. Rev. 28, 57-102. 